\title{
Tin Oxide Gas Sensor on Tin Oxide Microheater for Methane Sensing
}

\author{
Maryam Moalaghi ${ }^{1}$, Mohsen Gharesi ${ }^{1}$, Alireza Ranjkesh ${ }^{1}$ \\ ${ }^{1}$ Electronic Materials Laboratory, Electrical Engineering Department, K.N. Toosi University of \\ Technology, Tehran, 16317-14191, Iran. \\ mohsengharesi@email.kntu.ac.ir
}

\begin{abstract}
:
Despite the ever increasing demand for methane detection in residential and industrial locations, the common tin oxide-based methane sensors fail to satisfy the quality requirements for long-term operation in harsh environs. Particularly, the $\mathrm{RuO}_{2}$ microheaters utilized in these sensors deteriorate in reducing atmospheres and cannot provide the high temperatures required for methane detection in a long-time period. Here, we disclose a tin oxide gas sensor complete on a tin oxide microheater which can stably operate at temperatures as high as $850{ }^{\circ} \mathrm{C}$. Both components are produced by ultrasonic spray pyrolysis of tin chloride solution on alternative sites of an alumina chip. Thermally stable electrical contacts are formed by diffusion bonding of gold wire segments onto the $\mathrm{SnO}_{2}$ films. The response of the fabricated sensor to different methane concentrations is examined at operation temperatures in the $500-850{ }^{\circ} \mathrm{C}$ range. The device can detect $50 \mathrm{ppm}$ of methane in normal atmosphere with a response time of $10 \mathrm{~s}$, demonstrating suitability of the introduced sensor for online leakage detection applications.
\end{abstract}

Key words: Gas sensor, Microheater, Tin oxide, Spray pyrolysis, Electrical contact.

\section{Introduction}

The explosive nature of methane and its global warming issues have made detecting natural gas leakages important. Among the available leakage detection technologies, online leakage monitoring by chemoresistive gas sensors (CGSs) is advantageous as it provides a facile and economical route to safety. However, providing a stable means of supplying the elevated temperatures required for methane sensing is yet a technological challenge.

$\mathrm{RuO}_{2}$ microheaters commonly utilized in the CGS structures are susceptible to reducing atmospheres and their long-term operating temperature is limited to $400{ }^{\circ} \mathrm{C}[1,2]$. On the contrary, $\mathrm{SnO}_{2}$ microheaters operate durably at temperatures as high as $900{ }^{\circ} \mathrm{C}[1,3]$. $\mathrm{SnO}_{2}$ is also the base material of gas sensitive elements and its employment as microheater material reduces the total production costs.

Here, a CGS is introduced in which both the sensing element and the microheater are $\mathrm{SnO}_{2}$ films produced by ultrasonic spray pyrolysis (USP) deposition. The films' microstructure and thickness are engineered so that the sensing element resistively responds to the composition of the surrounding atmosphere while the microheater is insensitive to that.

\section{Experimental}

The USP system utilized for tin oxide deposition was described elsewhere [1]. The sensing element is composed of $\mathrm{SnO}_{2}$ nanoparticles produced by 1-minute spraying of a $0.05 \mathrm{M}$ ethanolic solution of $\mathrm{SnCl}_{2} \cdot 2 \mathrm{H}_{2} \mathrm{O}$ on an alumina chip heated to $320{ }^{\circ} \mathrm{C}$. The heating element is a $10 \mu \mathrm{m}$ thick tin oxide layer USP-deposited at $420{ }^{\circ} \mathrm{C}$ on the backside of the alumina substrate using a $0.2 \mathrm{M}$ solution of the same precursor [1]. The sample is then annealed at $900{ }^{\circ} \mathrm{C}$ in air for $1 \mathrm{~h}$ to stabilize the deposits.

Electrical contacts to both the sensing element and the microheater are formed by diffusion bonding of gold wire segments to the $\mathrm{SnO}_{2}$ films. The method has been proved to provide ohmic electrical contacts with fine thermal and mechanical stabilities [3]. Photograph and SEM images of a sample sensor are given in Fig. 1.

\section{Results and Discussion}

The sensor resistance reduces in reaction to the presence of methane gas in the surrounding atmosphere. The sensor response, defined as 


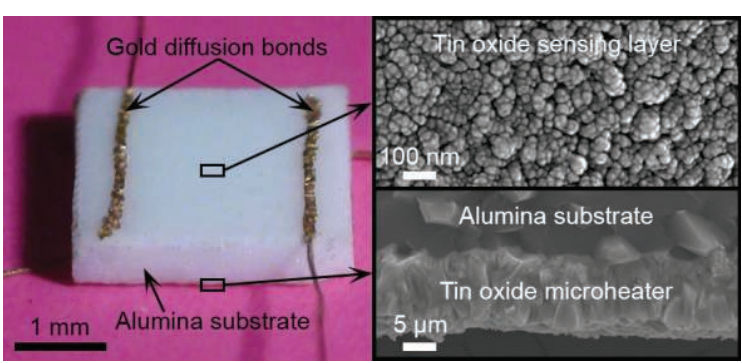

Fig. 1. Photograph and SEM micrographs of a sample tin oxide sensor.

the ratio of its resistance in air to that in a given $\mathrm{CH}_{4}$ concentration, is examined at operating tempratures in the $500-850{ }^{\circ} \mathrm{C}$ range and the results are represented in Fig. 2. The indicated error bars, derived from five consecuative exposure-recovery experiments, demonstrate repeatability of the sensor responses. Stability of the devices was tested by performing the same experiment on a sample continuously operated at $700{ }^{\circ} \mathrm{C}$ for 7 days; the resulting response alterations were in the range of the previously obtained error bars.

The sensing mechanism of CGSs is known to be thermally activated [4]; this leads to an increasing trend in the sensor response up to $800{ }^{\circ} \mathrm{C}$ for a constant methane concentration (see Fig. 2). At higher temperatures, dissociation of methane molecules far from the sensor surface and their partial conevrsion to $\mathrm{CO}_{2}[5]$ diminishes the sensor response.

The resitance variations induced by rapid exposure of the device operating at $800{ }^{\circ} \mathrm{C}$ to different methane concentrations are shown in Fig. 3. The sensor can detect $50 \mathrm{ppm}$ of methane with a response time of $10 \mathrm{~s}$ (see the inset in Fig. 3). The response time evaluated for the same methane concentration is 25,35 , and $44 \mathrm{~s}$ for operating temperatures of 750, 700 and $650{ }^{\circ} \mathrm{C}$, respectively. The increase in the response time with reducing the temperature is in accordance with the thermal activation of the sensing process [4].

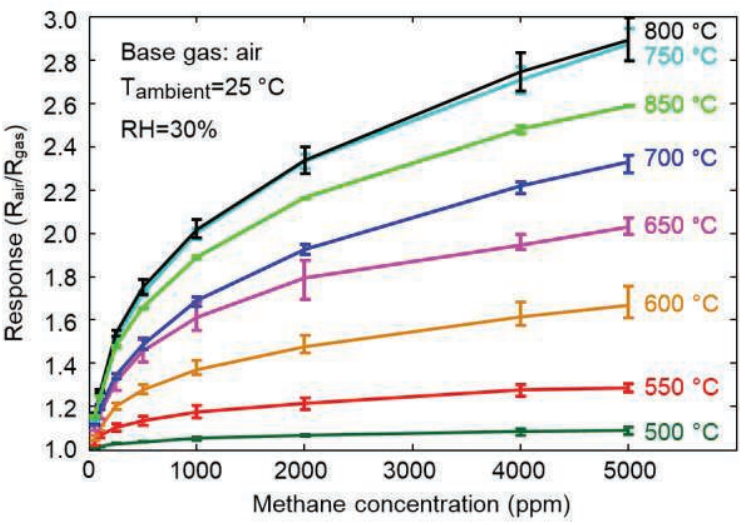

Fig. 2. Response of a sample sensor vs. methane concentration at different operating temperatures.

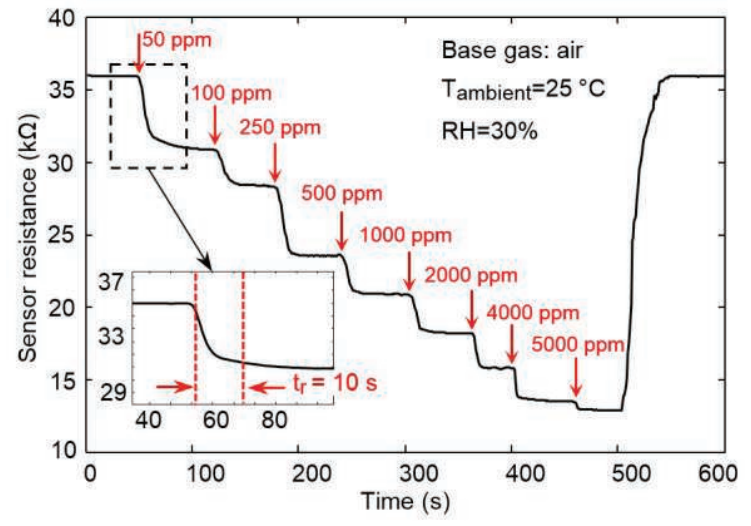

Fig. 3. Temporal resistance variations of a sample $\mathrm{SnO}_{2}$ sensor operating at $800{ }^{\circ} \mathrm{C}$ in response to its exposure to different methane concentrations.

\section{Conclusions}

A sturdy gas sensor suitable for fast detection of minute methane concentrations was introduced in which both the sensing layer and the microheater were USP-deposited tin oxide films. The required ohmic electrical contacts were formed by direct diffusion bonding of gold wires to the $\mathrm{SnO}_{2}$ layers. The fabricated sensor exhibited a wide dynamic range of $50-5000$ $\mathrm{ppm}$. Owing to the oxide nature of the structure and stability of the formed electrical contacts, the device can reliably function at harsh environmental conditions.

\section{References}

[1] F. Hossein-Babaei, M. Gharesi, M. Ansari, Ten Micron-Thick Undoped $\mathrm{SnO}_{2}$ Layers Grown by Spray Pyrolysis for Microheater Fabrication, Materials Letters 196, 104-107 (2017); doi: 10.1016/j.matlet.2017.03.015

[2] A.A. Vasiliev, A.V. Pisliakov, A.V. Sokolov, N.N. Samotaev, S.A. Soloviev, K. Oblov, V. Guarnieri, L. Lorenzelli, J. Brunelli, A. Maglione, A.S. Lipilin, A. Mozalev, A.V. Legin, Non-Silicon MEMS Platforms for Gas Sensors, Sensors and Actuators B: Chemical 224, 700-713 (2016); doi: 10.1016/j.snb.2015.10.066

[3] F. Hossein-Babaei, M. Gharesi, M. Moalaghi, Diffusion Bonding of Metal Wires Directly to the Functional Metal Oxide Semiconductors for Forming Reliable Electrical Contacts, ACS Applied Materials \& Interfaces 9, 26637-26641 (2017); doi: 10.1021/acsami.7b07825

[4] V. Brinzari, G. Korotcenkov, "Kinetic Approach to Receptor Function in Chemiresistive Gas Sensor Modeling of Tin Dioxide. Steady state Consideration Sensors and Actuators B: Chemical 259, 443-454 (2018); doi: 10.1016/j.snb.2017.12.023

[5] T. Sahm, W. Rong, N. Bârsan, L. Mädler, U. Weimar, Sensing of $\mathrm{CH}_{4}, \mathrm{CO}$ and Ethanol with in situ Nanoparticle Aerosol-Fabricated Multilayer Sensors Sensors and Actuators B: Chemical 127, 63-68 (2007); doi: 10.1016/j.snb.2007.07.001 